\title{
The prognostic influence of intrapancreatic tumor location on survival after resection of pancreatic ductal adenocarcinoma
}

\author{
Dietrich A. Ruess ${ }^{1}$, Frank Makowiec ${ }^{1}$, Sophia Chikhladze ${ }^{1}$, Olivia Sick¹, Hartwig Riediger², Ulrich T. Hopt ${ }^{1}$ \\ and Uwe A. Wittel ${ }^{1 *}$
}

\begin{abstract}
Background: The prognosis of pancreatic ductal adenocarcinoma (PDAC) is worse when the tumor is located in the pancreatic body or tail, compared to being located in the pancreatic head. However, for localized, resectable tumors survival seems to be at least similar.

Methods: We analyzed and compared the outcome after pancreatoduodenectomy (PD) and distal pancreatectomy (DP) for PDAC at our institution. Clinical, pathological and survival data from patients undergoing pancreatic resection for PDAC 1994-2014 were explored retrospectively, accessing a prospective pancreatic database. Patients receiving primary total pancreatectomy were excluded.

Results: Four hundred and thirteen patients were treated for PDAC: 347 (84 \%) underwent PD and 66 (16 \%) DP. Tumors located in the pancreatic body and tail were significantly larger than their counterparts located in the head (30.6 mm vs. $41.2 \mathrm{~mm} ; p<0.001$ ). However, distal tumors had significantly less nodal involvement (71 \% vs. 57 \%; $p=0.03$ ). Portal-vein resection (PVR) was performed more often in PD, multivisceral resection (MVR) was more frequent in DP (37 \% vs. $14 \%$ and $4 \%$ vs. $29 \% ; p<0.001$ ). Rates for negative resection margins and tumor grading were similar. Postoperative complication rates including morbidity, rates of re-operation and mortality were comparable. Long-term outcome revealed no significant difference between PD and DP with 5-year survival rates of 17.8 and $22 \%$ respectively $(p=0.284)$. Multivariate analysis confirmed positive resection margin, positive nodal status, extended resection (PVR, MVR) and lack of adjuvant/additive chemotherapy as independent risk factors for poor survival after pancreatic resection.
\end{abstract}

Conclusion: Patients with resectable pancreatic ductal adenocarcinoma located in the body and tail of the pancreas display a similar postoperative oncological outcome despite larger tumors when compared to patients with resectable tumors located in the pancreatic head.

Keywords: Pancreatic cancer, Pancreatoduodenectomy, Distal pancreatectomy, Survival, Outcome

\section{Background}

Prognosis for pancreatic cancer (PC) has only slightly improved over the past decades and still is grim, with a current 5-year relative survival rate of about $6.9 \%[1,2]$. Stratified by tumor site, mortality is even worse when the tumor is located in the pancreatic body and tail. A

\footnotetext{
* Correspondence: uwe.wittel@uniklinik-freiburg.de

${ }^{1}$ Department of Surgery, University of Freiburg, Freiburg, Germany Full list of author information is available at the end of the article
}

recent analysis based on SEER-data (Surveillance, Epidemiology and End Results Program by the National Cancer Institute, NCI, U.S.) revealed a significant difference in the 3-year survival rates of $3.9 \%$ (body/tail) vs. $6.2 \%$ (head) [3]. This observation is most likely due to delayed diagnosis in the case of tumor location in the pancreatic body and tail, since early symptoms are usually lacking. Therefore, a significantly higher percentage of patients is primarily diagnosed with advanced disease and stage IV PC (body/tail: 56-73\% vs. head: 26-39 \%) $[3,4]$, where surgical therapy is not beneficial. Complete
C Biomed Central

(c) 2015 Ruess et al. Open Access This article is distributed under the terms of the Creative Commons Attribution 4.0 International License (http://creativecommons.org/licenses/by/4.0/), which permits unrestricted use, distribution, and reproduction in any medium, provided you give appropriate credit to the original author(s) and the source, provide a link to the Creative Commons license, and indicate if changes were made. The Creative Commons Public Domain Dedication waiver (http://creativecommons.org/publicdomain/zero/1.0/) applies to the data made available in this article, unless otherwise stated. 
resection at an early stage though, is the most important factor in multimodal treatment and the only chance for cure and long-term survival [5]. In combination with adjuvant chemotherapy, 5-year survival rates of up to $15-30 \%$ can be achieved [6-9].

In the case of localized and resectable disease, some observational studies analyzing the outcome by tumor stage at diagnosis show superior survival for patients with cancer located in the pancreatic body/tail compared to patients with cancer located in the pancreatic head [3, 4]. A NCD-report (National Cancer Database, American College of Surgeons Commission on Cancer and American Cancer Society) pictures a 5-year survival-rate of $32 \%$ (tail) vs. $11 \%$ (head) for stage I disease (for stage II and stage III disease $12 \%$ (tail) vs. $6 \%$ (head) and $11 \%$ (tail) vs. $7 \%$ (head), respectively) [4]. However, when recently a surgical collective of patients after pancreatic resection for adenocarcinoma was examined, the survival benefit for patients with resectable disease located in the body and tail detected in these observational studies could yet not be confirmed [10]. In this and other studies, despite significantly larger size of tumors located in the body/tail, survival after proximal pancreatectomy and distal pancreatectomy was similar [6, 10-13].

To clarify these putative contradictions, our aim was to retrospectively examine our own single-institution collective regarding survival after resection for pancreatic ductal adenocarcinoma (PDAC). We intended to identify risk factors influencing survival in patients undergoing distal pancreatectomy (DP) or pancreatoduodenectomy (PD) for PDAC.

\section{Methods}

\section{Patients}

From July 1994 to December 2014, 413 patients with primary non-metastasized pancreatic adenocarcinoma were eligible for surgery (PD or DP) in our department (patients requiring total pancreatectomy were not included). 347 were treated by pancreatoduodenectomy and 66 by distal pancreatectomy.

\section{Surgical technique and pathological analysis}

Whenever possible, the pylorus was preserved during pancreatoduodenectomy. Complete lymphadenectomy was performed in the hepatic ligament, right of the celiac trunk and right of the mesenteric artery. Venous structures were resected whenever necessary to achieve complete resection. Intraoperative histopathologic evaluation was routinely performed at common bile duct and pancreatic resection margin. In recent years the mesopancreatic retroperitoneal margin was also examined. Other margins underwent frozen section analysis if intraoperatively indicated, such as in case of venous resection at both venous resection margins. In distal pancreatectomy with splenectomy, lymphadenectomy was performed left of the celiac trunk and left of the mesenteric artery. Since 2005 resection was performed as described by Strasberg et al. $[8,14,15]$ including the fascia of Gerota and when indicated the left adrenal gland. Intraoperative histopathologic evaluation was performed at the pancreatic resection margin. After formalin fixation, standard histopathological evaluation was performed on all operative specimens in which tumor size, lymph node status and resection margin were assessed. Negative resection margin was defined as tumor remote to the resection margin independent of the exact distance.

Since 2006 laparoscopic procedures for DP as well as PD increased in number. Pancreatic stump management (DP) and reconstruction (PD) were accomplished via mini-laparotomy.

\section{Perioperative therapy}

Neoadjuvant therapy was administered, in a few cases $(n=22)$ with locally advanced disease since year 2000, predominantly as radiochemotherapy. Postoperative adjuvant treatment was heterogeneous. In the early study phase adjuvant therapy was not routinely performed after curative resection. Since 2003 a few selected patients were included in studies. Later, due to evidence from randomized trials (European Study Group for Pancreatic Cancer: ESPAC-1 Trial) [16], adjuvant chemotherapy was regularly recommended and administered. In case of positive resection margins postoperative chemoradiation or additive chemotherapy was administered whenever applicable, preferentially in clinical trials.

\section{Follow-up and statistical analysis}

Perioperative data was collected prospectively in a SPSS database (IBM Corp. Released 2013. IBM SPSS Statistics for Windows, Version 22.0. Armonk, NY: IBM Corp.) The survival status was achieved from general practitioners or oncologists (until 2001) and regional cancer registries (since 2001). Data collection and analysis were performed in accordance with the Helsinki guidelines and approved by the local ethics committee (Ethik-Kommission of the Albert-Ludwigs-Universtität Freiburg), the need for individual verbal or written informed consent from participants or their next of kin was waived. Statistical analysis was performed with SPSS. In addition to descriptive statistics, inferential analysis $\left(\chi^{2}\right.$-test for categorical variables or Mann-Whitney-U-test for continuous variables) and Kaplan-Meier survival analyses with log-rank-test for the comparison of subgroups, multivariate analysis (Cox proportional hazards model) was performed to determine independent risk factors.

\section{Results}

Of the 413 resected patients nine $(2.2 \%)$ died due to postoperative complications, seven were lost to follow- 
up. Therefore, 16 patients were excluded for survival analysis (11 patients from the PD-group and 5 patients from the DP-group). Survival was analyzed in the remaining 397 patients. Of those, 336 patients received PD while 61 patients were treated with DP. Median postoperative follow-up was 14 months (13 months for deceased patients; 16 months for censored patients).

\section{Patient characteristics}

In both groups patient characteristics were not significantly different in regard to gender, age and body mass index (Table 1).

\section{Surgery}

Regarding duration of surgery, a significant difference was detectable with PDs showing to be more timeconsuming (PD: 440 (245-760) min vs. DP: 301 (140717) min [median (range)]). If blood transfusions were necessary, the volume administered was significantly higher in the PD-group (PD: $423 \pm 729 \mathrm{ml}$ vs. DP: $192 \pm$ $368 \mathrm{ml}[$ mean $\pm \mathrm{SD}])$. The intraoperative involvement of the superior mesenteric vein or portal vein with a subsequent resection was higher in patients with tumors located in the pancreatic head (PD: $37 \%$ vs. DP: $14 \%$ ). In contrast, multivisceral resections were performed more frequently in patients with tumors located in the

Table 1 Demographic, surgical, pathological and postoperative data from 413 patients undergoing pancreatic resection for pancreatic ductal adenocarcinoma (1994-2014)

\begin{tabular}{|c|c|c|c|}
\hline & Pancreaticoduodenectomy & Distal pancreatectomy & $p$ \\
\hline $\mathrm{N}$ of resections & 347 & 66 & \\
\hline Gender & & & 0.755 \\
\hline Male & 182 [52 \%] & $36[55 \%]$ & \\
\hline Female & 165 [48 \%] & 30 [45 \%] & \\
\hline Age in years median (range) & $67.0(31-89)$ & $65.6(35-88)$ & 0.362 \\
\hline $\mathrm{BMI}$ in $\mathrm{kg} / \mathrm{m}^{2}$ median (range) & $24.4(7.6-38.8)$ & $23.6(18.2-35.4)$ & 0.725 \\
\hline Operation time in min median (range) & $440(245-760)$ & $301(140-717)$ & $<0.001$ \\
\hline \multirow[t]{2}{*}{$\mathrm{PRBC}$ receivedif received, vol. in $\mathrm{ml}$ mean $( \pm S D)$} & 135 [39\%] & 17 [27 \%] & 0.056 \\
\hline & $423( \pm 729)$ & $192( \pm 368)$ & 0.024 \\
\hline \multicolumn{4}{|l|}{ Extended resection } \\
\hline - none & 204 [59 \%] & 38 [58 \%] & $<0.001$ \\
\hline - portal vein & 128 [37 \%] & 9 [14\%] & \\
\hline - multivisceral & $15[4 \%]$ & 19 [29\%] & \\
\hline Free resection margin & $247[71 \%]$ & 46 [73 \%] & 0.767 \\
\hline \multicolumn{4}{|l|}{ Grading $^{a}$} \\
\hline G1 & 11 [3\%] & 5 [9\%] & 0.229 \\
\hline G2 & 194 [57 \%] & 28 [51 \%] & \\
\hline G3 & 128 [38 \%] & $21[38 \%]$ & \\
\hline G4 & 6 [2 \%] & 1 [2 \%] & \\
\hline Tumor size in mm median (range) & $28(1-130)$ & $38(5-110)$ & $<0.001$ \\
\hline Node positive & 246 [71\%] & $35[57 \%]$ & 0.030 \\
\hline $\mathrm{N}$ of analyzed nodes median (range) & $15(2-47)$ & $15(2-32)$ & 0.783 \\
\hline Any complication & 181 [52 \%] & 32 [49\%] & 0.584 \\
\hline Surgical complication & $123[35 \%]$ & 20 [30 \%] & 0.421 \\
\hline - POPF & 48 [14 \%] & 25 [38 \%] & $<0.001$ \\
\hline$-\mid A A$ & $25[7 \%]$ & 8 [12\%] & 0.177 \\
\hline$-\mathrm{SSI}$ & $44[13 \%]$ & 6 [9\%] & 0.413 \\
\hline Re-operation & 33 [10 \%] & 10 [15 \%] & 0.169 \\
\hline Mortality & 7 [2 \%] & 2 [3\%] & 0.605 \\
\hline Adjuvant/additive chemotherapy & 188 [54 \%] & 35 [53 \%] & 0.864 \\
\hline
\end{tabular}

$B M I$ body mass index, PRBC packed red blood cells, POPF postoperative pancreatic fistula, IAA intraabdominal abscess, SSI surgical site infection ${ }^{a}$ Data for Tumor grading was not available for 19 patients (PD: 8 patients; DP: 11 patients) 
pancreatic body and tail (PD: 4 \% vs. DP: $29 \%)$. Here atypical gastric resections and colon resections were mostly performed (data not shown). Resection of the left adrenal gland was considered as frequent part of the procedure for DP, therefore adrenalectomy was neglected when analyzing for multivisceral resections (Table 1).

\section{Pathologic diagnosis}

Tumors located in the pancreatic body and tail were significantly larger than tumors located in the pancreatic head (PD: 28 (1-130) mm vs. DP: 38 (5-110) mm [median (range)]. Despite larger tumors, margin negative (R0) resection was achieved with an equal rate (PD: $71 \%$ vs. DP: 73 \%). Histopathologic evaluation showed a comparable distribution of tumor grading. However, nodal involvement was less frequent when the tumor was located in the pancreatic body/tail (rate of N+: PD: $71 \%$ vs. DP: $57 \%$, with similar median number of analyzed nodes) (Table 1$)$.

\section{Postoperative course}

Postoperative complications of any kind and surgery related complications like pancreatic fistula, intraabdominal abscess, or wound infection were not significantly different between the two groups. However, evaluation by specific surgical complication revealed significance for a higher pancreatic fistula rate after distal resection. Necessity of re-operation and mortality (PD: $2 \%$ vs. DP: $3 \%$ ) was similar (Table 1).

\section{Adjuvant/additive therapy}

Two-hundred and twenty-three patients received or were referred to oncologists to receive postoperative chemotherapy. Twenty-two of these had additionally been treated with neoadjuvant therapy for locally advanced, initially unresectable tumors; 62 had positive resection margins. The remaining group of 175 comprised patients who were either not treated in an adjuvant/ additive manner (historical cohort or due to morbidity) or for whom this data was lacking. The rate of adjuvantly/additively treated patients did not differ between the PD- (54 \%) and DP-group (53\%) (Table 1).

\section{Survival}

The entire group of 397 patients showed an overall 3and 5-year survival after pancreatic resection of 29.5 and $18.3 \%$ respectively with a median survival of 20.6 months (95 \% CI: 17.4-23.8).

A trend to increased survival $(p=0.284)$ was observed in patients after surgery for tumors located in the pancreatic body and tail compared to those located in the pancreatic head. The 3- and 5-year survival rates of patients after pancreatoduodenectomy were 27.3 and $17.8 \%$ compared to 45.5 and $22 \%$ in patients treated with distal pancreatectomy. The median survival in patients after PD and DP was 20.4 months $(95 \% \mathrm{CI}$ : 17.4-23.8) and 24.4 months (95\% CI: 2.9-45.8), respectively (Table 2 and Fig. 1).

In the subgroups with negative resection margin 3year and 5-year survival rates were 33.7 and $21.1 \%(\mathrm{PD})$ vs. 54.2 and $25.3 \%(\mathrm{DP})$, respectively $(p=0.212)$. In the case of margin-positive resection, survival was considerably worse with 3-year and 5-year survival rates of 13 and $11.2 \%$ after PD vs. $17.5 \%$ vs. $0 \%$ after DP $(p=0.370)$ (Fig. 2).

The Strasberg-approach for distal resection was performed since 2005 on 20 out of 61 patients with follow-up data. We could not detect a difference in survival between the historical and the Strasberg-cohort (data not shown).

Adjuvant/additive chemotherapy significantly improved oncological outcome after pancreatic surgery for PDAC. The group of patients who received or intended to receive adjuvant/additive therapy demonstrated a median survival of 25.8 months (95 \% CI: 20.6-31.0). However, patients who did not receive adjuvant/additive therapy or for whom this information was lacking had a median survival of only 18 months (95\% CI: 14.9-21.1). 3-year and 5-year survival rates were 37.3 and $14.9 \%$ (received/intended to receive) vs. $22 \%$ and $15.7 \%$ (not received/unknown), respectively $(p=0.010)$ (Table 2 and Fig. 3 ).

\section{Risk factors for survival}

In univariate analysis resection margin, nodal disease, extent of resection (portal vein and/or multivisceral), blood transfusion and adjuvant/additive chemotherapy showed significant impact on survival after pancreatic resection for PDAC. No effect was observed for patient gender, age and BMI. Furthermore, tumor size, tumor grading and the presence of postoperative complications also did not significantly affect survival (Table 2 ).

Multivariate survival analysis revealed resection margin, nodal disease, extended resection, and adjuvant/ additive chemotherapy as independent risk factors for survival after pancreatic resection for PDAC (Table 3).

\section{Discussion}

Although stage-independent overall survival is worse for distally located pancreatic cancer, better long-term outcome for localized tumors of the pancreatic body/tail has been reported. This is probably due to surgical approaches. Delayed diagnosis of pancreatic cancer, when the tumor is located in the pancreatic body or tail, leads to a higher number of patients not being amenable to resection. Especially the lack of specific symptoms such as jaundice is responsible for that fact. Most likely, decreased survival is rather due to systemic spread and metastasis than to local unresectability. When located in the pancreatic body and tail, compared to the pancreatic 
Table 2 Overall survival after resection for pancreatic ductal adenocarcinoma. Univariate survival analysis of 397 patients

\begin{tabular}{|c|c|c|c|c|}
\hline Parameter & $n$ & 3-year-survival & 5-year-survival & $p$ \\
\hline All & 397 & $29.5 \%$ & $18.3 \%$ & \\
\hline \multicolumn{5}{|l|}{ Tumor location } \\
\hline Head & 336 & $27.3 \%$ & $17.8 \%$ & \\
\hline Distal & 61 & $45.4 \%$ & $22.0 \%$ & 0.284 \\
\hline \multicolumn{5}{|l|}{ Gender } \\
\hline Male & 190 & $29.3 \%$ & $15.8 \%$ & \\
\hline Female & 207 & $29.7 \%$ & $20.2 \%$ & 0.683 \\
\hline \multicolumn{5}{|l|}{ Age } \\
\hline$>65$ years & 225 & $30.4 \%$ & $22.6 \%$ & \\
\hline$<65$ years & 172 & $28.3 \%$ & $13.8 \%$ & 0.493 \\
\hline \multicolumn{5}{|l|}{$\mathrm{BMI}^{\mathrm{a}}$} \\
\hline$>25 \mathrm{~kg} / \mathrm{m}^{2}$ & 161 & $26.3 \%$ & $13.7 \%$ & \\
\hline$<25 \mathrm{~kg} / \mathrm{m}^{2}$ & 235 & $31.2 \%$ & $20.9 \%$ & 0.494 \\
\hline \multicolumn{5}{|l|}{ Tumor size ${ }^{a}$} \\
\hline$<30 \mathrm{~mm}$ & 223 & $28.8 \%$ & $18.4 \%$ & \\
\hline$>30 \mathrm{~mm}$ & 157 & $30.4 \%$ & $16.9 \%$ & 0.860 \\
\hline \multicolumn{5}{|l|}{ Tumor grading $^{a}$} \\
\hline Grade $1+2$ & 230 & $29.6 \%$ & $18.7 \%$ & \\
\hline Grade $3+4$ & 151 & $26.5 \%$ & $15.3 \%$ & 0.191 \\
\hline \multicolumn{5}{|l|}{ Resection margin ${ }^{a}$} \\
\hline RO & 283 & $36.2 \%$ & $21.7 \%$ & \\
\hline $\mathrm{R}+$ & 113 & $13.5 \%$ & $9.9 \%$ & $<0.001$ \\
\hline \multicolumn{5}{|l|}{ Nodal status ${ }^{a}$} \\
\hline Negative & 121 & $41.1 \%$ & $27.7 \%$ & \\
\hline Positive & 272 & $22.9 \%$ & $13.0 \%$ & 0.001 \\
\hline \multicolumn{5}{|l|}{ Extended resection } \\
\hline None & 233 & $35.9 \%$ & $26.1 \%$ & \\
\hline Portal Vein (PV) & 133 & $21.5 \%$ & $7.9 \%$ & \\
\hline More than PV, multivisceral & 31 & $12.8 \%$ & $0 \%$ & $<0.001$ \\
\hline \multicolumn{5}{|l|}{ PRBC transfusion ${ }^{a}$} \\
\hline Yes & 143 & $22.4 \%$ & $15.6 \%$ & \\
\hline No & 252 & $33.8 \%$ & $19.2 \%$ & 0.005 \\
\hline \multicolumn{5}{|l|}{ Any complication } \\
\hline Yes & 200 & $31.1 \%$ & $17.2 \%$ & \\
\hline No & 197 & $27.8 \%$ & $18.7 \%$ & 0.916 \\
\hline \multicolumn{5}{|l|}{ Surgical complication } \\
\hline Yes & 133 & $37.0 \%$ & $18.1 \%$ & \\
\hline No & 264 & $25.9 \%$ & $17.4 \%$ & 0.149 \\
\hline \multicolumn{5}{|l|}{ Adjuvant/additive chemotherapy } \\
\hline Yes/Intended ${ }^{b}$ & 222 & $37.3 \%$ & $14.9 \%$ & \\
\hline No/Unknown & 175 & $22.0 \%$ & $15.7 \%$ & 0.010 \\
\hline
\end{tabular}

$B M I$ body mass index, $P R B C$ packed red blood cells

${ }^{\text {a }}$ Some parameters were not available for individual patients (BMI: 1 patient; Tumor size: 17 patients; Tumor grading: 16 patients; Resection margin: 1 patient; Nodal status: 4 patients; PRBC transfusion: 2 patients)

${ }^{\mathrm{b}}$ Included are 22 patients with (additional) neoadjuvant therapy and 62 patients with additive therapy 


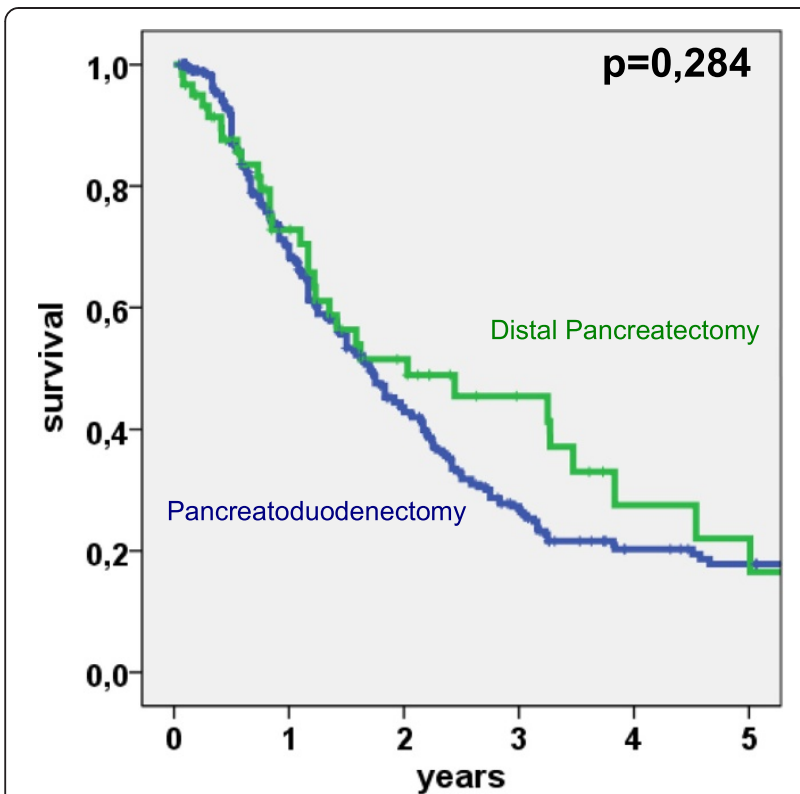

Fig. 1 Kaplan-Meier plot: Survival analysis of 397 patients after pancreatic resection for pancreatic ductal adenocarcinoma. Patients after pancreatoduodenectomy $(n=336)$ vs. patients after distal pancreatectomy $(n=61)$. 3-year and 5-year survival rates are 27,3 and $17.8 \%$ (PD) vs. 45.4 and $22 \%$ (DP). $p=0.284$

head, larger tumors can be resected more frequently and successfully, as measured by the rate of margin-free resections. In spite of larger tumor size, similar long-term outcome for DP and PD has been noted [6, 10-13].

One reason for this might be a favorable tumor biology of resectable PDAC of the pancreatic body/tail. Although the tumor grade usually increases with tumor size [6], this could not be demonstrated in our analysis. However, others have reported similar data with proximal tumors showing more dedifferentiation in spite of smaller size [17]. Similar to our study, nodal involvement seems

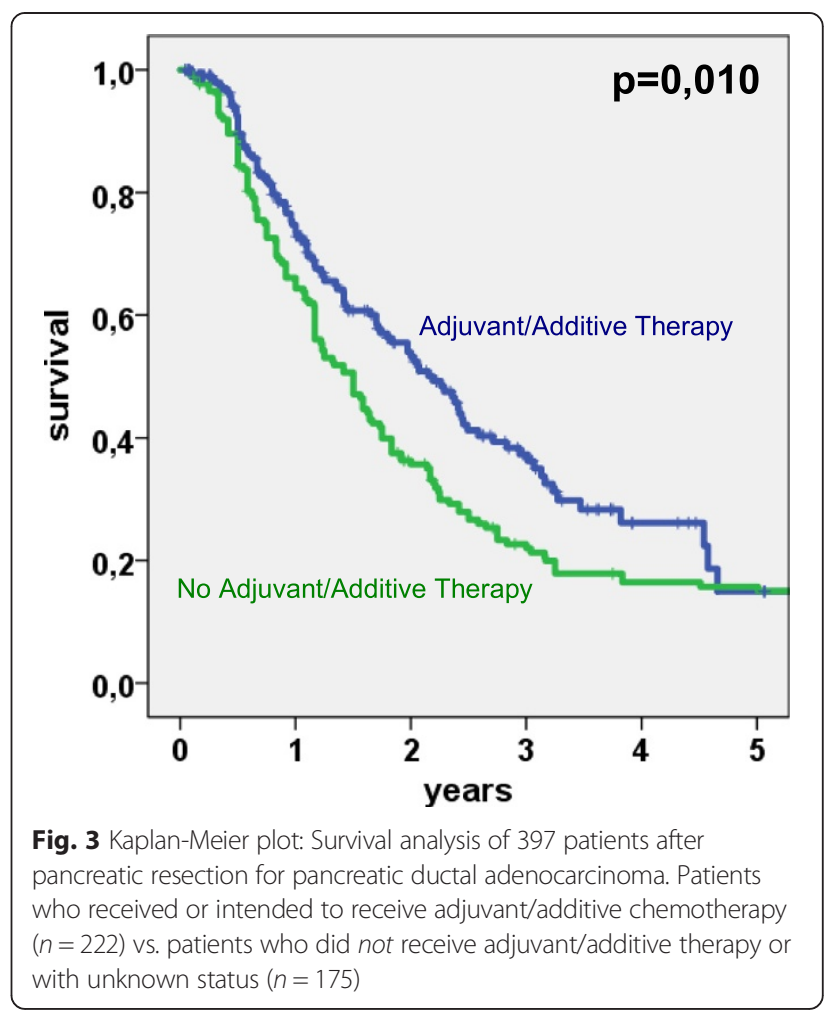

to be less frequent in resectable distal tumors $[6,17]$. Confirmed here as independent risk factor, nodal disease is well known to negatively correlate with survival [18-23].

Furthermore, technical advances in form of the radical antegrade modular pancreatosplenectomy, described by Strasberg et al. [14], may achieve higher rates of marginfree resection. This has probably contributed to improved survival-rates after DP in recent years [24]. Five-yearsurvival-rates of up to $30 \%$ are reported $[8,21]$. However, in our cohort we could not detect a survival benefit related to this procedure.

\section{a) negative margin}

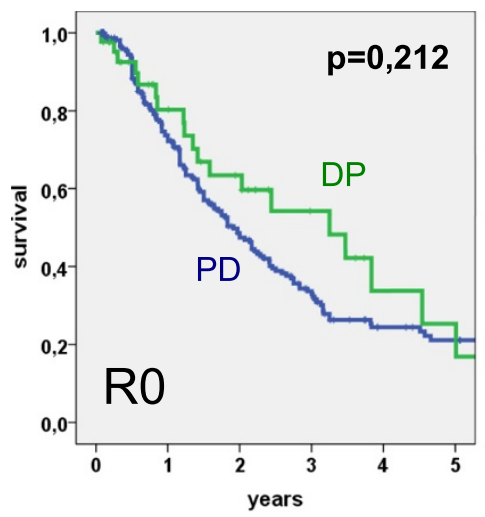

\section{b) positive margin}

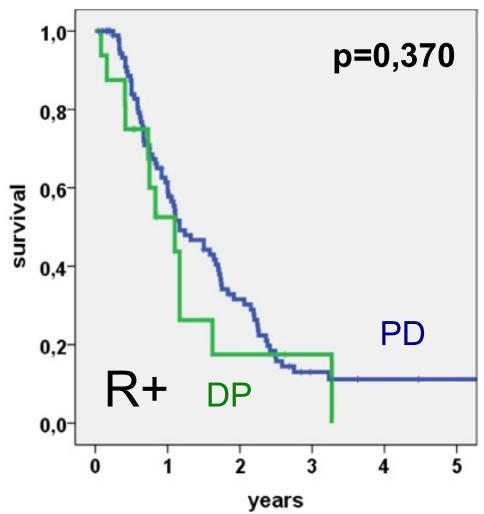

Fig. 2 Kaplan-Meier plot: Survival analysis stratified by resection margins. a Patients with negative resection margin (R0), after pancreatoduodenectomy $(\mathrm{PD}, n=239)$ vs. distal pancreatectomy (DP, $n=44)$. b Patients with positive resection margin $(\mathrm{R}+)$, after PD $(n=97)$ vs. DP $(n=16)$ 
Table 3 Multivariate analysis. Independent risk-factors for poor survival after pancreatic resection (pancreatoduodenectomies and distal pancreatectomies) for pancreatic ductal adenocarcinoma

\begin{tabular}{llll}
\hline & $P$-value & RR & $95 \%-\mathrm{Cl}$ \\
\hline Positive resection margin & $<0.001$ & 1.7 & $1.3-2.2$ \\
Positive nodal status & $<0.01$ & 1.5 & $1.1-2.0$ \\
Extended resection & & & \\
$\quad$ - none & - & 1 & \\
- Portal Vein (PV) & $<0.001$ & 2.7 & $1.7-4.3$ \\
- more than PV (multivisceral) & $<0.005$ & 2.2 & $1.4-3.6$ \\
No adjuvant/additive chemotherapy & $<0.05$ & 1.4 & $1.1-1.8$ \\
(or unknown) & & & \\
\hline
\end{tabular}

Another factor is the possibility of resecting adjacent organs when involved in the tumor. Patients with tumors located in the pancreatic body and tail benefit from the fact that technically, distal pancreatectomies can be easily performed together with en bloc gastric or colon resections. Without the involvement of vital structures as in the case of the pancreatic head with its anatomical proximity to important vessels, this extended, or multivisceral resection is not only feasible but also safe and justified [25-27]. Our pooled data for PD and DP demonstrate that survival after portal vein (PVR) and especially multivisceral (MVR) resection is worse in contrast to the standard procedure. However, this observation may be biased by the skewed dataset in favor of PDs where MVR or extended resection for pancreatic head cancer is associated with increased perioperative risk and with worse oncological outcome [28]. In our study significantly more patients were able to undergo multivisceral resections when presenting with tumors of the pancreatic body/tail. Morbidity and mortality were not different between the two groups. Rates of margin-free resection were similar. As our data undermine (Table 2+3, Fig. 2), R0-resection is the mainstay of surgical therapy and one of the most important factors influencing long-term outcome $[6,17$, $19,29,30]$. However, it is to be completed by adjuvant chemotherapy (Table $2+3$, Fig. 3) whenever possible [9].

Although this study is limited by its retrospective character, in summary our collective demonstrates similar postoperative oncological outcome for patients with resectable pancreatic ductal adenocarcinoma located in the body/tail or head of the pancreas. Therefore, the overall poorer survival in patients with tumors located in the pancreatic body or tail appears to be solely due to delayed diagnosis of disease with advanced stage and limited therapeutic options.

\section{Conclusion}

Patients with resectable pancreatic ductal adenocarcinoma located in the body and tail of the pancreas display a similar postoperative oncological outcome despite larger tumors when compared to patients with resectable tumors located in the pancreatic head.

\section{Competing interests}

No funding was received for this study. The authors declare no conflict of interest.

\section{Authors' contributions}

DAR interpreted data and drafted the manuscript. FM carried out data analysis, helped to interpret data and to draft the manuscript. OS performed data collection and administration. UAW conceived the study, participated in interpretation of data and assisted in drafting the manuscript. SC, HR and UTH revised critically and approved the final manuscript. All authors read and approved the final manuscript.

\section{Acknowledgements}

The article processing charge was funded by the German Research Foundation (DFG) and the Albert Ludwigs University Freiburg in the funding program Open Access Publishing.

\section{Author details}

${ }^{1}$ Department of Surgery, University of Freiburg, Freiburg, Germany. ${ }^{2}$ Department of Surgery, Vivantes-Humboldt-Clinic, Berlin, Germany.

Received: 15 June 2015 Accepted: 23 November 2015

Published online: 28 November 2015

\section{References}

1. Siegel RL, Miller KD, Jemal A. Cancer statistics, 2015. CA Cancer J Clin. 2015; 65:5-29.

2. Sun $H$, Ma H, Hong G, Sun $H$, Wang J. Survival improvement in patients with pancreatic cancer by decade: a period analysis of the SEER database, 1981-2010. Sci Rep. 2014;4:6747.

3. Lau MK, Davila JA, Shaib YH. Incidence and survival of pancreatic head and body and tail cancers: a population-based study in the United States. Pancreas. 2010;39:458-62.

4. Sener SF, Fremgen A, Menck HR, Winchester DP. Pancreatic cancer: a report of treatment and survival trends for 100,313 patients diagnosed from 1985-1995, using the National Cancer Database 1. J Am Coll Surg. 1999;189:1-7.

5. Wagner M, Redaelli C, Lietz M, Seiler CA, Friess H, Büchler MW. Curative resection is the single most important factor determining outcome in patients with pancreatic adenocarcinoma. Br J Surg. 2004;91:586-94.

6. Sohn TA, Yeo CJ, Cameron JL, Koniaris L, Kaushal S, Abrams RA, et al. Resected adenocarcinoma of the pancreas - 616 patients: results, outcomes, and prognostic indicators. J Gastrointest Surg. 2000;4:567-79.

7. Franko J, Hugec V, Lopes TL, Goldman CD. Survival among pancreaticoduodenectomy patients treated for pancreatic head cancer $<1$ or 2 cm. Ann Surg Oncol. 2013;20:357-61.

8. Mitchem JB, Hamilton N, Gao F, Hawkins WG, Linehan DC, Strasberg SM. Long-term results of resection of adenocarcinoma of the body and tail of the pancreas using radical antegrade modular pancreatosplenectomy procedure. J Am Coll Surg. 2012;214:46-52.

9. Jones OP, Melling JD, Ghaneh P. Adjuvant therapy in pancreatic cancer. World J Gastroenterol. 2014;20:14733-46.

10. Toomey P, Hernandez J, Golkar F, Ross S, Luberice K, Rosemurgy A. Pancreatic adenocarcinoma: complete tumor extirpation improves survival benefit despite larger tumors for patients who undergo distal pancreatectomy and splenectomy. J Gastrointest Surg. 2012;16:376-81.

11. Dalton RR, Sarr MG, van Heerden JA, Colby TV. Carcinoma of the body and tail of the pancreas: is curative resection justified? Surgery. 1992;111:489-94.

12. Brennan MF, Moccia RD, Klimstra D. Management of adenocarcinoma of the body and tail of the pancreas. Ann Surg. 1996;223:506-11. discussion 511-512.

13. Sperti C, Pasquali C, Piccoli A, Pedrazzoli S. Survival after resection for ductal adenocarcinoma of the pancreas. Br J Surg. 1996;83:625-31.

14. Strasberg SM, Drebin JA, Linehan D. Radical antegrade modular pancreatosplenectomy. Surgery. 2003;133:521-7. 
15. Strasberg SM, Linehan DC, Hawkins WG. Radical antegrade modular pancreatosplenectomy procedure for adenocarcinoma of the body and tail of the pancreas: ability to obtain negative tangential margins. J Am Coll Surg. 2007;204:244-9.

16. Neoptolemos JP, Stocken DD, Friess H, Bassi C, Dunn JA, Hickey H, et al. A randomized trial of chemoradiotherapy and chemotherapy after resection of pancreatic cancer. N Engl J Med. 2004;350:1200-10.

17. Moon HJ, An JY, Heo JS, Choi SH, Joh JW, Kim Yl. Predicting survival after surgical resection for pancreatic ductal adenocarcinoma. Pancreas. 2006;32:37-43.

18. Shimada K, Sakamoto Y, Sano T, Kosuge T. Prognostic factors after distal pancreatectomy with extended lymphadenectomy for invasive pancreatic adenocarcinoma of the body and tail. Surgery. 2006;139:288-95.

19. Kooby DA, Hawkins WG, Schmidt CM, Weber SM, Bentrem DJ, Gillespie TW, et al. A multicenter analysis of distal pancreatectomy for adenocarcinoma: is laparoscopic resection appropriate? J Am Coll Surg. 2010;210:779-85. 786-787.

20. Fujita T, Nakagohri T, Gotohda N, Takahashi S, Konishi M, Kojima M, et al. Evaluation of the prognostic factors and significance of lymph node status in invasive ductal carcinoma of the body or tail of the pancreas. Pancreas. 2010;39:e48-54

21. Paye F, Micelli Lupinacci R, Bachellier P, Boher J-M, Delpero J-R, French Surgical Association (AFC). Distal pancreatectomy for pancreatic carcinoma in the era of multimodal treatment. Br J Surg. 2015;102:229-36.

22. Riediger H, Keck T, Wellner U, Zur Hausen A, Adam U, Hopt UT, et al. The lymph node ratio is the strongest prognostic factor after resection of pancreatic cancer. J Gastrointest Surg Off I Soc Surg Aliment Tract. 2009;13:1337-44

23. Ashfaq A, Pockaj BA, Gray RJ, Halfdanarson TR, Wasif N. Nodal counts and lymph node ratio impact survival after distal pancreatectomy for pancreatic adenocarcinoma. J Gastrointest Surg Off J Soc Surg Aliment Tract. 2014;18:1929-35.

24. Parikh PY, Lillemoe KD. Surgical management of pancreatic cancer-distal pancreatectomy. Semin Oncol. 2015;42:110-22.

25. Shoup M, Conlon KC, Klimstra D, Brennan MF. Is extended resection for adenocarcinoma of the body or tail of the pancreas justified? J Gastrointest Surg Off J Soc Surg Aliment Tract. 2003;7:946-52. discussion 952.

26. Christein JD, Kendrick ML, Iabal CW, Nagorney DM, Farnell MB. Distal pancreatectomy for resectable adenocarcinoma of the body and tail of the pancreas. J Gastrointest Surg Off J Soc Surg Aliment Tract. 2005:9:922-7.

27. Roch AM, Singh H, Turner AP, Ceppa EP, House MG, Zyromski NJ, et al. Extended distal pancreatectomy for pancreatic adenocarcinoma with splenic vein thrombosis and/or adjacent organ invasion. Am J Surg. 2015; 209:564-9.

28. Kulemann B, Hoeppner J, Wittel U, Glatz T, Keck T, Wellner UF, et al. Perioperative and long-term outcome after standard pancreaticoduodenectomy, additional portal vein and multiviscera resection for pancreatic head cancer. J Gastrointest Surg Off J Soc Surg Aliment Tract. 2015:19:438-44.

29. Yamamoto J, Saiura A, Koga R, Seki M, Katori M, Kato Y, et al. Improved survival of left-sided pancreas cancer after surgery. Jpn J Clin Oncol. 2010;40:530-6.

30. Kang CM, Kim DH, Lee WJ. Ten years of experience with resection of left-sided pancreatic ductal adenocarcinoma: evolution and initial experience to a laparoscopic approach. Surg Endosc. 2010;24:1533-41.

\section{Submit your next manuscript to BioMed Central and we will help you at every step:}

- We accept pre-submission inquiries

- Our selector tool helps you to find the most relevant journal

- We provide round the clock customer support

- Convenient online submission

- Thorough peer review

- Inclusion in PubMed and all major indexing services

- Maximum visibility for your research 